\title{
Sequential reduction of UV-B radiation in the field alters the pigmentation of an Antarctic leafy liverwort
}

\author{
K.K. Newsham ${ }^{\star}$, P.A. Geissler, M.J. Nicolson, H.J. Peat \& R.I. Lewis-Smith
}

Natural Environment Research Council, British Antarctic Survey, Cambridge CB3 OET, UK

* Corresponding author. Tel.: +44-1223-221400; fax: +44-1223-362616. E-mail address: kne@bas.ac.uk

\begin{abstract}
UV-B radiation (280-315 nm) incident on the leafy liverwort Cephaloziella varians growing at Rothera Point on the Western Antarctic Peninsula was manipulated in late austral spring 1998 by screens consisting of a novel combination of plexiglass panes and polyester sheets. The screens transmitted c. $79 \%, 68 \%, 48 \%, 41 \%$ and $31 \%$ of daily UV-B radiation dose. Plants from under and outside the screens were sampled seven times over $35 \mathrm{~d}$. Correlative analyses indicated that concentrations of an anthocyanin-like pigment located in leaf tips were positively associated with UV-B transmission at the last two samplings, that concentrations of total chlorophylls were negatively associated with UV-B transmission at the final sampling, and that those of UV-B screening pigments were positively correlated with transmission at three intermediate samplings. Chlorophyll $a$ / $b$ ratio did not respond to the applied treatment. Plants exposed to low UV-B transmission levels were visibly greener than those exposed to high transmission levels after approximately $23 \mathrm{~d}$. The closest fits between the treatment and concentrations of UV-B screening pigments were associated with increased ambient biologically-weighted UV-B dose received by plants in the $5.5 \mathrm{~h}$ before each sampling, which coincided with the passage of the ozone hole over Rothera Point. As C. varians emerged from melting snow and ice, concentrations of the anthocyanin-like pigment and chlorophyll respectively increased and decreased faster in plants exposed to high transmission levels of UV-B, relative to those exposed to low UV-B transmission levels.
\end{abstract}


Keywords: anthocyanin, Cephaloziella varians, chlorophyll, stratospheric ozone depletion, UV-B screening pigments

\section{Introduction}

Post and Vesk (1992) demonstrated that the dark purple form of the Antarctic leafy liverwort Cephaloziella varians (Gottsche) Steph., which is found in sunlit locations, accumulates a dark wall-bound anthocyanin-like pigment in its leaf tips and contains less chlorophyll than the green form, which is found in shaded habitats. Previous research suggests that these differences in the pigmentation of $C$. varians between sunlit and shaded habitats may be owing to exposure to UVB (280-315 nm) radiation. The accumulation of anthocyanins and related pigments in plant tissues is often induced by exposure to UV-B radiation, through the induction of genes encoding key enzymes in the phenylpropanoid biosynthesis pathway (Mol et al., 1996). Exposure to UV-B has also been shown to reduce chlorophyll concentrations in plant tissues (e.g. Ruhland and Day, 2001), although this is not a generic response across a broad range of plant species (Searles et al., 2001; Robinson et al., 2003). Further research suggests that other pigments in $C$. varians tissues also respond to UV-B exposure: concentrations of UV-B screening pigments, which, along with anthocyanins, are products of the phenylpropanoid biosynthesis pathway, correlate significantly in $C$. varians tissues with rapid between-day fluctuations in UV-B doses received by plants at Rothera Point on the Western Antarctic Peninsula (Newsham et al., 2002). This observation implied that these pigments respond within $24 \mathrm{~h}$ of exposure to UV-B radiation, demonstrating a remarkably rapid response to an environmental factor in such a cold habitat (Newsham et al., 2002).

In order to explicitly test whether these changes to the pigmentation of $C$. varians are induced by solar UV-B radiation, we deployed a novel combination of plexiglass panes and polyester sheets over the liverwort growing at Rothera Point in late austral spring 1998. Similar studies in Antarctica have used single-factor ANOVA analyses to compare the responses of plants under acrylic screens providing a reduced UV-B treatment with those under a near-ambient and an ambient UV-B control (e.g. Ruhland and Day, 2000, 2001; Lud et al., 2003). However the 
design of the screens used in the present study allowed us to examine dose-response relationships between UV-B exposure and pigment concentrations with correlative analyses. Late spring 1998 on the Antarctic Peninsula was characterised by early melt of snow and ice covering vegetation, frequent cloudless skies and the regular passage over the region of the Antarctic 'ozone hole', i.e., a mass of stratospheric air depleted in ozone (Farman et al., 1985), making it an ideal period in which to determine the effects of UV-B radiation on plant pigmentation in the natural environment.

\section{Materials and methods}

\subsection{Screen design and deployment}

UV-B doses received by plants were manipulated in situ by the use of 10 screens. Each screen consisted of two juxtaposed $3 \mathrm{~mm}$ thick plexiglass panes $(0.65 \times 0.65 \mathrm{~m}$; GS2458, Röhm GmbH \& Co. KG, Darmstadt, Germany), which transmitted the majority of UV-B radiation $(67 \%, 93 \%$ and $95 \%$ transmission at $280 \mathrm{~nm}, 300 \mathrm{~nm}$ and $315 \mathrm{~nm}$, respectively), placed onto nuts which were screwed onto studding fixed to angle aluminium struts (Fig. 1). Eight of the 10 screens each had a $100 \mu \mathrm{m}$ thick Mylar polyester sheet $(0.6 \times 0.6$ m; A.R. Warne \& Co., Ltd., London, UK), which strongly absorbed UV-B radiation (0\% and 3.5\% transmission at $313 \mathrm{~nm}$ and $315 \mathrm{~nm}$, respectively), mounted between the two plexiglass panes. The use of a plexiglass pane either side of the polyester sheeting ensured that it withstood the strong winds that regularly occur at Rothera Point. Two of these eight screens received an intact Mylar sheet, and, to achieve a doseresponse surface suitable for correlative analysis, the remaining six screens received Mylar sheets from which 25 equidistant holes of three different diameters had been cut (Fig. 1). Each of two screens received Mylar from which $48 \mathrm{~mm}, 68 \mathrm{~mm}$ and $96 \mathrm{~mm}$ diameter holes had been cut, which removed $12.5 \%, 25 \%$ and $50 \%$ of the surface area of Mylar, respectively. These screens are hereafter referred to as small, medium and large hole screens, respectively. Those not containing Mylar and those containing intact Mylar sheets are hereafter referred to as no Mylar and full Mylar screens, respectively. Rubber tubing was placed onto the studding either side of 
the plexiglass panes to protect them from mechanical damage and wing nuts were placed onto the studding to secure the panes (Fig. 1).

The 10 screens were deployed over $C$. varians growing amongst the moss Sanionia uncinata in an unshaded, low-lying gully fed by meltwater at Rothera Point on the Wright Peninsula, Adelaide Island, western Antarctic Peninsula (67 $34^{\prime} \mathrm{S}, 68^{\circ} 07^{\prime} \mathrm{W}$ ) on 17 November 1998. Plants had emerged from melting ice and snow during the preceding week. Meltwater from a nearby ice cornice was the principal source of water for plants during the study: snow events were infrequent and rainfall did not occur, obviating the need for perforated screens, which are used at lower latitudes to allow precipitation to reach plants (e.g. Robson et al., 2003). Screen surfaces were angled at $c .12^{\circ}$ to the horizontal and the lowest edge of the screens faced northwards to attenuate maximum UV-B radiation at solar noon. Rocks from the gully were placed over the ends of the aluminium struts in order to weigh the screens down. The Mylar sheets were replaced weekly on the day after each sampling to ensure that the transmission properties of the polyester did not alter during the course of the experiment. Strong winds dislodged a large hole screen early in the experiment. This screen was excluded from further analyses.

In order to estimate the dose of UV-B radiation received by plants under screens, two broad band UV-B sensors (SKU 430; Skye Instruments Ltd., Llandrindod Wells, UK) were connected to a datalogger (CR10; Campbell Scientific Ltd., Loughborough, UK), one sensor was placed under the centre of a screen placed in the gully from which plants were sampled and the other sensor was placed in an unshaded location $1.5 \mathrm{~m}$ from the screen. The sensors had a peak response at $290 \mathrm{~nm}$ and were cosine corrected with minimal error below angles of $70^{\circ}$ to the perpendicular and small $(<5 \%)$ errors between $70^{\circ}$ and $80^{\circ}$. Sensor output was recorded for $24 \mathrm{~h}$ under each of the five types of screens during cloudless days in January and February.

\subsection{Sampling and pigment analyses}

Samples of three $C$. varians colonies $(c .25 \mathrm{~mm} \times 25 \mathrm{~mm})$ were removed from as close as possible to the centre of each screen, to avoid edge effects, <30 min. after deployment. Three 
larger $(c .50 \mathrm{~mm} \times 50 \mathrm{~mm})$ samples of $C$. varians were also collected at positions within the gully not shaded by screens or the ice cornice. Samples were placed into plastic bags and kept in the dark prior to pigment extraction. Triplicate samples from under each screen and from unshaded areas in the gully were then collected at solar noon (13:30 hrs local time) on 19 and 24 November 1998 and at 7 d intervals thereafter until 22 December 1998. The samples were returned to a laboratory c. $500 \mathrm{~m}$ from the gully in which the screens were deployed. The uppermost 2-3 mm of foliage was cut from each sample and, to facilitate grinding, it was blotted on absorbent paper until no free water could be drawn from the tissues (Post and Vesk, 1992). Preliminary analyses, using the spectrophotometric methods described below, indicated that this process removed c. $2 \%$ of the pigments analysed for in this study from tissues. Samples from the same screen were combined, and each sample, including the three separate samples from outside the screens, was then divided into three $c .100 \mathrm{mg}$ subsamples. Two of the subsamples were ground separately with $c .1 .5 \mathrm{~g}$ of silver sand in a mortar with a pestle for $0.5 \mathrm{~min}$. To extract chlorophylls, $3 \mathrm{ml}$ of methanol was added to the first subsample and the tissues were ground for $1 \mathrm{~min}$. The extracts were then centrifuged at $6000 \mathrm{rpm}$ for $10 \mathrm{~min}$ at $0{ }^{\circ} \mathrm{C}$ and $700 \mu$ of these extracts were passed through $0.45 \mu \mathrm{m}$ filters (Whatman International Ltd., Maidstone, UK). To extract UV-B screening pigments and the anthocyanin-like pigment, $3 \mathrm{ml}$ of a 70:20:1 mixture of methanol, water and $\mathrm{HCl}$ was added to the second subsample and the tissues were ground for $1 \mathrm{~min}$ (Post and Vesk, 1992). The extracts were heated at $65{ }^{\circ} \mathrm{C}$ for $10 \mathrm{~min}$ and were then centrifuged at 6000 rpm for $10 \mathrm{~min}$, the supernatants removed and placed in a refrigerator, and a further $1 \mathrm{ml}$ of the methanol, water and $\mathrm{HCl}$ mixture was added to the pellet, which was resuspended before heating again at $65^{\circ} \mathrm{C}$ for $10 \mathrm{~min}$. The supernatants were combined and $700 \mu \mathrm{l}$ of the extracts passed through $0.45 \mu \mathrm{m}$ filters. The third subsample was dried to constant weight $\left(60^{\circ} \mathrm{C}\right.$ for $\left.48 \mathrm{~h}\right)$ to enable pigment data to be expressed on a per g dry weight basis.

Extracts were transferred to UV grade polymethyl methacrylate semi-microcuvettes (PMMA; Kartell spa, Milan, Italy), diluted and absorbances were measured immediately in a spectrophotometer. To estimate concentrations of chlorophylls $a$ and $b$, absorbances of methanol extracts were measured at 653 and $666 \mathrm{~nm}$ and concentrations of pigments calculated from 
standard formulae (Lichtenthaler and Wellburn, 1983). Weights of total chlorophyll (i.e., chlorophyll $a+b$ ) extracted per g dry weight of tissue and chlorophyll $a$ / $b$ ratios were subsequently calculated. To estimate concentrations of UV-B screening pigments, the absorbance of each acidified methanol extract was measured between 280 and $315 \mathrm{~nm}$ (step $1 \mathrm{~nm}$ ). The concentration of the anthocyanin-like pigment was estimated by measuring the absorbance of acidified methanol extracts at $495 \mathrm{~nm}$ (Post and Vesk, 1992). Concentrations of UV-B screening pigments were expressed in arbitrary units as the area under the absorbance curve ( $\left.\mathrm{AUC}_{280-315}\right)$ per g dry weight of tissue. Data for the anthocyanin-like pigment were expressed in arbitrary units as $\mathrm{A}_{495}$ per g dry weight. Sample preparation and analyses were conducted in dim light and were usually completed within $2 \mathrm{~h}$ of sampling.

\subsection{Ozone column, irradiance and temperature measurements}

Overpass measurements of ozone column depth over Rothera Point (Fig. 2a) for 16 November 12 December 1998 were obtained from the Earth Probe Total Ozone Mapping Spectrometer (EPTOMS) through the world wide web (http://jwocky.gsfc.nasa.gov). Global spectral irradiance (280-600 nm, step $0.5 \mathrm{~nm}$ ) was recorded between 16 November and 18 December 1998 by a double monochromator grating spectroradiometer (Bentham DM150; Bentham Instruments Ltd., Reading, UK) situated in the laboratory in which pigment analyses were made. The instrument recorded data every $30 \mathrm{~min}$ between 08:00 and 19:00 hrs local time. The spectroradiometer was calibrated against a $1000 \mathrm{~W}$ quartz-halogen tungsten coil filament lamp that had been calibrated relative to National Institute of Standards and Technology standards. Data from the instrument were not available for 25 and 26 November 1998 and 19-22 December. Spectral data for these days were recorded at Palmer Station on Anvers Island, situated c. $380 \mathrm{~km}$ north of Rothera Point. Studies indicate close rank correlations between daily doses of UV-B and PAR received at the two locations $\left(r_{\mathrm{s}}=0.94\right.$ and 0.92 , respectively, both $P<0.001, n=689$; H.J. Peat et al., unpublished). Spectral data were expressed as the daily doses of biologically effective UV-B $\left(\mathrm{UV}-\mathrm{B}_{\mathrm{BE}}\right)$, weighted with the generalized plant action spectrum (Caldwell 1971) and normalized at $300 \mathrm{~nm}$ (Fig. 2b), or PAR (Fig. 2c). Ambient air temperatures (Fig. 2d) were recorded every 5 
min. during the experiment by two platinum resistance thermometers (PT100; Labfacility Ltd., Teddington, UK), within a Stevenson screen situated c. $300 \mathrm{~m}$ from the gully in which the screens were deployed. The temperatures of the uppermost $2-3 \mathrm{~mm}$ of colonies outside screens and under a no Mylar screen were recorded at each sampling, except on 17 November, with a hand-held digital thermometer with a penetration probe (Checktemp HI98501; Hanna Instruments Inc., Woonsocket, RI, USA).

\subsection{Statistical analyses}

Associations between plant pigmentation and percentage UV-B transmission at each sampling, including the time zero sampling on 17 November, were tested by Pearson's product-moment correlations. Mean values derived from each treatment level and from uncovered plants were entered into these analyses (hence $d . f .=5$ ). Correlative analyses were also used to test the closeness of fit between correlation coefficients $(r)$ derived from these analyses for pigments at each sampling and ambient UV- $\mathrm{B}_{\mathrm{BE}}$ received by plants 5.5, 24 and $48 \mathrm{~h}$ before each sampling. Regression analyses were used to determine the slopes for the associations between time (day) and mean pigment concentrations or chlorophyll $a$ / $b$ ratio at each UV-B transmission level. Standard errors of slopes derived from these analyses were then used to compare differences in pigment accumulation or loss under different UV-B transmission levels.

\section{Results}

\subsection{Screen performance}

The screens used in our study sequentially reduced daily doses of UV-B radiation: analyses of data obtained from the broad band sensors indicated that no Mylar, large, medium, small hole and full Mylar screens transmitted c. 79\%, 68\%, 48\%, 41\% and 31\% of daily UV-B dose, respectively (Fig. 3a). Optimal attenuation of UV-B radiation was achieved at solar noon, with minimal attenuation in the early morning and late evening when the Sun was at its lowest elevation (Fig. 3b). During overcast periods on 19 and 24 November, and 8 and 22 December, the mean temperatures of colonies at noon under and outside screens were $2.2^{\circ} \mathrm{C}$ and $1.9^{\circ} \mathrm{C}$, 
respectively. Under cloudless skies at noon on 1 and 15 December, the mean temperatures of colonies under and outside screens were $17.4^{\circ} \mathrm{C}$ and $13.1^{\circ} \mathrm{C}$, respectively.

\subsection{Plant pigmentation}

Pigment concentrations or chlorophyll $a$ / $b$ ratio were not significantly associated with percentage UV-B transmission on 17 November (Table 1). However, there were significant positive associations between UV-B transmission and the concentration of the anthocyanin-like pigment at the final two samplings on 15 and 22 December (Table 1, Fig. 4a, b). In contrast, concentrations of total chlorophyll were negatively associated with UV-B transmission on 22 December (Table 1, Fig 4c). These changes in concentrations of chlorophyll and the anthocyaninlike pigment were evident from visual inspection of the plants: after 10 December, those under full Mylar screens were greener than those under no Mylar screens and those from outside screens. Chlorophyll $a$ / $b$ ratio did not respond to the sequential reduction in UV-B radiation (Table 1). The concentrations of UV-B screening pigments were positively associated with UV-B transmission on 1, 8 and 15 December (Table 1, Fig. 4d-f).

The closeness of fit between UV-B transmission level and concentrations of UV-B screening pigments was associated with the recent UV-B environment, which was in turn associated with ozone column depth over Rothera Point (Fig. 2a, inset): there was a significant positive association between $r$ values derived for UV-B screening pigments (Table 1) and UV-

$\mathrm{B}_{\mathrm{BE}}$ dose received $5.5 \mathrm{~h}$ before sampling took place (Fig. 4f, inset). Associations between $r$ values for UV-B screening pigments and UV- $\mathrm{B}_{\mathrm{BE}}$ dose received $24 \mathrm{~h}$ and $48 \mathrm{~h}$ before sampling were not significant. Similarly, there were no significant associations between UV-B ${ }_{B E}$ dose received 5.5 h, $24 \mathrm{~h}$ or $48 \mathrm{~h}$ before sampling and $r$ values derived for chlorophyll, chlorophyll $a$ / $b$ ratio or the anthocyanin-like pigment (data not shown).

Regression analyses indicated that slopes for the associations between time and chlorophyll $a / b$ ratio, concentrations of UV-B screening pigments or the anthocyanin-like pigment, were all positive (Table 2). The slopes were significant at the 100\% and 79\% UV-B transmission levels for concentrations of UV-B screening pigments and the anthocyanin-like pigment, respectively, 
and at the $41 \%$ and $48 \%$ UV-B transmission levels for chlorophyll concentrations (Table 2). Concentrations of the anthocyanin-like pigment increased faster in plants exposed to the $79 \%$ UV-B transmission level than in those exposed to the $31 \%$ transmission level (Table 2). In contrast, chlorophyll accumulated faster during the study in plants exposed to the $31 \%, 41 \%$ and $48 \%$ UV-B transmission levels, compared with plants exposed to the $68 \%$ and $100 \%$ transmission levels (Table 2). Although these analyses indicated no effects of UV-B transmission level on changes in chlorophyll $a$ / $b$ ratio over the course of the experiment (Table 2), we recorded a consistent rise in this ratio at all transmission levels from 1.45 on 17 November to 2.46 on 8 December $(r=0.973, P=0.005)$.

\section{Discussion}

Our study demonstrates that a sequential reduction of UV-B radiation dose in the natural environment alters the pigmentation of $C$. varians. It shows that the accumulation of the anthocyanin-like pigment in sun-exposed $C$. varians reported by Post and Vesk (1992) most probably arises from exposure to UV-B radiation: after 28 and $35 \mathrm{~d}$, tissues of plants exposed to low doses of UV-B radiation contained substantially less of the anthocyanin-like pigment than those exposed to high doses. Similar effects of UV-B radiation on the accumulation of anthocyanins in plant tissues are well documented (Chalker-Scott, 1999). Furthermore, our study indicates that the reduced chlorophyll concentrations in sun-exposed $C$. varians tissues reported by Post and Vesk (1992) are also most probably owing to UV-B radiation exposure. After 35 d, chlorophyll concentrations in tissues of plants exposed to reduced UV-B were almost twice those of tissues exposed to high doses of UV-B. Although many studies have recorded no effect of UVB radiation on chlorophyll concentrations in plant tissues (Searles et al., 2001), this is not an unprecedented result: for example, concentrations of chlorophyll $b$ are reduced by $46 \%$ in leaves of Antarctic Pearlwort (Colobanthus quitensis) exposed to ambient UV-B, compared with leaves of plants exposed to reduced UV-B (Ruhland and Day, 2001).

These effects of UV-B on plant pigmentation at individual samplings were supported by an analysis of pigmentation under different UV-B transmission levels over the course of the 
experiment. These analyses indicated that the concentration of the anthocyanin-like pigment increased faster in plants exposed to high UV-B doses, relative to plants exposed to reduced irradiances of UV-B. Conversely, chlorophyll concentrations increased in plants exposed to low UV-B doses and the pigment was lost from plants exposed to high doses. These data suggest that, in a similar response to juvenile reddening of emerging herbaceous seedlings (Chalker-Scott, 1999), exposure to UV-B radiation induces the production of the anthocynanin-like pigment in $C$. varians tissues as plants emerge from melting snow and ice at the end of austral spring, and that chlorophyll may be lost from tissues at this time. During this period we also recorded a rise in chlorophyll $a$ / $b$ ratio from 1.45 to 2.46 , the same value as that recorded by Post and Vesk (1992). This is analogous to the response recorded by Martin and Churchill (1982), who found that chlorophyll $a$ / $b$ ratio declined in a range of mosses after canopy closure in a temperate forest. However our data suggest that exposure to UV-B radiation is unlikely to explain the change in this ratio over the course of our experiment.

Our study shows that $C$. varians increases the synthesis of UV-B screening pigments with increased exposure to UV-B radiation. This observation corroborates those from previous experiments into the effects of UV-B radiation on Antarctic vascular plants: higher concentrations of UV-B screening pigments have been consistently recorded in tissues of $C$. quitensis and Antarctic Hairgrass (Deschampsia antarctica) exposed to near-ambient or ambient UV-B radiation, relative to plants exposed to reduced UV-B (Ruhland and Day, 2000; Ruhland and Day, 2001; Xiong and Day, 2001). It also corroborates previous data showing positive associations between concentrations of UV-B screening pigments in $C$. varians tissues and daily doses of UV-B ${ }_{\mathrm{BE}}$ received at Rothera Point (Newsham et al., 2002). The data reported by Newsham et al. (2002) were based upon correlations between plant pigmentation and UV-B exposure over 60 days, increasing the degrees of freedom in statistical analyses to an order of magnitude greater than in the present study. It is hence difficult to make a direct comparison between these data and those from the current study. However both studies indicate that exposure to UV-B radiation elicits the production of UV-B screening pigments in $C$. varians foliage. This is the most consistent response of a wide range of plant species to elevated UV-B in outdoor 
irradiation experiments (Searles et al. 2001).

Although we used lower replication here than in our previous study, the present data further support the view that $C$. varians apparently responds to rapid fluctuations in UV-B irradiance (Newsham et al., 2002): the best fits between UV-B transmission level and concentrations of UV-B screening pigments were associated with the dose of UV- $\mathrm{B}_{\mathrm{BE}}$ radiation received on the morning prior to each sampling. This suggests that UV-B screening pigments responded more consistently to the treatment under depleted ozone columns and indicates that the pigmentation of these plants may have responded within several hours of exposure to UV-B radiation. Despite daily mean air temperatures of between -5 and $2{ }^{\circ} \mathrm{C}$, the temperature of $C$. varians colonies beneath screens reached $17{ }^{\circ} \mathrm{C}$ under cloudless skies, which would have enabled rapid responses of plant pigmentation to the rapidly-fluctuating radiative environment. Studies on temperate plant species also indicate rapid responses of UV-B screening pigments to changes in UV-B radiation. For example, the induction of messenger RNA transcripts encoding for flavonoids, a common group of UV-B screening pigments in plant tissues, occurs within several hours of exposure to UV-B radiation (Jordan et al., 1994).

Given the apparent speed of response of UV-B screening pigments to the fluctuating UV-B environment at Rothera Point, it is probable that these pigments play a role in protecting $C$. varians from elevated UV-B radiation (Newsham et al., 2002). The majority of UV-B screening pigments in plant tissues are products of the phenylpropanoid biosynthesis pathway, and hence contain carbon ring structures which are efficient at absorbing UV-B radiation (Cockell and Knowland, 1999). However, although anthocyanins and related pigments are also products of the same pathway and contain ring structures, they only absorb UV-B inefficiently (Chalker-Scott, 1999; Cockell \& Knowland 1999). The anthocyanin-like pigment present in C. varians tissues, although it may be induced by UV-B exposure, is hence unlikely to offer substantial protection from UV-B radiation. Furthermore, the pigment does not apparently respond to rapidlyfluctuating UV-B irradiances. This view is supported by the absence of correlations between the closeness of fit of the treatment on concentrations of the pigment and doses of ambient UV- $\mathrm{B}_{\mathrm{BE}}$ radiation received by plants in this study. Concentrations of the pigment in plants sampled at 
noon from outside screens on 43 consecutive days in spring and summer 1998 are also not associated with daily doses or noon irradiances of solar UV-B received at Rothera Point (K. Newsham, unpubl.). Similarly, chlorophyll did not appear to respond rapidly to UV-B exposure in our study, as there were no associations between the closeness of fit of the treatment on chlorophyll concentrations and doses of $U V-B_{\mathrm{BE}}$ received by plants. Our data indicate that the reduced concentration of this pigment observed at high UV-B doses in our study may have been a long-term response to the treatment. This view corroborates the data of Newsham et al. (2002), who concluded that chlorophyll concentrations in $C$. varians tissues were not associated with rapidly-changing UV-B irradiances received by plants at Rothera Point.

The screens used in our study were ineffective at attenuating UV-B radiation when the Sun was at a low elevation. Poor attenuation of UV-B radiation at these times could have been eliminated by the use of vertical walls at the sides and backs of screens. However, previous studies have found that under cloudless skies such walls result in up to $20{ }^{\circ} \mathrm{C}$ increases in the temperatures of plants and soil beneath screens relative to ambient (Kennedy 1995). Hence, in our study, we chose to omit walls from screens and found that under cloudless skies the temperatures of colonies beneath screens were only up to $4.9^{\circ} \mathrm{C}$ higher than of those outside screens. It is possible that these differences in the temperatures of colonies under and outside the screens may have influenced pigment concentrations, but concentrations of pigments in plant tissues under no Mylar screens and in plants from outside screens were similar, increasing our confidence that these temperature increases had little influence on pigment concentrations.

Although the screens used in the present study were successful at sequentially reducing the daily doses of UV-B radiation received by plants, future studies may benefit from making accurate PAR measurements under screens and from modifying the design of screens used here. Simultaneous measurements of UV-B and PAR received by plants under screens would enable UV-B to PAR ratio to be calculated for each transmission level, which would allow an examination of the relationship between this variable and concentrations of pigments, such as carotenoids, which are associated with UV-B to PAR ratio in C. varians (Newsham et al., 2002). Changes to the number and size of holes in the polyester might also improve screen performance. 
The current design of screen would have led to heterogeneous effects on the irradiances of UV-B received by individual plants throughout each day. For example, a plant beneath an area of Mylar polyester in a small, medium or large hole screen would have received substantially less direct UV-B irradiance at solar noon than during periods when the zenith angle of the Sun enabled the plant to receive direct irradiance through the holes in the polyester. This would have introduced heterogeneity into plant response to the changing UV-B irradiances throughout each day. Future studies using the technique described here might hence be improved by the use of polyester sheets from which differing numbers of holes of equal but small size are cut. This would, at least to some extent, reduce the heterogeneous effect of the screens on the irradiances of UV-B received by plants throughout each day.

\section{Acknowledgements}

Funding from the UK Natural Environment Research Council and support from staff at Rothera research base, particularly Roger Worland and Rod Arnold, are gratefully acknowledged. Ozone data were supplied gratis by the NASA/GSFC TOMS Ozone Processing Team. UV data from Palmer station were provided by the NSF UV Monitoring Network, operated by Biospherical Instruments Inc. under a contract from the United States National Science Foundations' Office of Polar Programs via Raytheon Polar Services Company. 


\section{References}

Caldwell, M.M., 1971. Solar UV radiation and the growth and development of higher plants. In: Giese, A.C. (Ed), Photophysiology, vol. 6. Academic Press, New York, pp. 131-177.

Chalker-Scott, L., 1999. Environmental significance of anthocyanins in plant stress responses. Photochem. Photobiol. 70, 1-9.

Cockell, C.S., Knowland, J., 1999. Ultraviolet radiation screening compounds. Biol. Rev. 74, 311-345.

Farman, J.C., Gardiner, B.G., Shanklin, J.D., 1985. Large losses of total ozone in Antarctica reveal seasonal $\mathrm{ClO}_{\mathrm{x}} / \mathrm{NO}_{\mathrm{x}}$ interaction. Nature 315, 207-210.

Jordan, B.R., James, P.E., Strid, A., Anthony, R.G., 1994. The effect of ultraviolet-B radiation on gene expression and pigment composition in etiolated and green pea leaf tissue: UV-B-induced changes are gene-specific and dependent upon the development stage. Plant Cell Environ. 17, 4554.

Kennedy, A.D., 1995. Simulated climate change: are passive greenhouses a valid microcosm for testing the biological effects of environmental perturbations? Glob. Change Biol. 1, 29-42.

Lichtenthaler, H.K., Wellburn, A.R., 1983. Determination of total carotenoids and chlorophylls $a$ and $b$ of leaf extracts in different solvents. Biochem. Soc. Trans. 11, 591-592.

Lud, D., Schlensog, M., Schroeter, B., Huiskes, A.H.L., 2003. The influence of UV-B radiation on light-dependent photosynthetic performance of Sanionia uncinata (Hedw.) Loeske in Antarctica. Polar Biol. 26, 225-232. 
Martin, C.E., Churchill, S.P., 1982. Chlorophyll concentrations and $a / b$ ratios in mosses collected from exposed and shaded habitats in Kansas. J. Bryol. 12, 297-304.

Mol, J., Jenkins, G., Schäfer, E., Weiss, D., 1996. Signal perception, transduction, and gene expression involved in anthocynanin biosynthesis. Crit. Rev. Plant Sci. 15, 525-557.

Newsham, K.K., Hodgson, D.A., Murray, A.W.A, Peat, H.J., Lewis-Smith, R.I., 2002. Response of two Antarctic bryophytes to stratospheric ozone depletion. Glob. Change Biol. 8, 972-983.

Post, A., Vesk, M., 1992. Photosynthesis, pigments and chloroplast ultrastructure of an Antarctic liverwort from sun-exposed and shaded sites. Can. J. Bot. 70, 2259-2264.

Robinson, S.A., Wasley, J., Tobin, A.K., 2003. Living on the edge - plants and global change in continental and maritime Antarctica. Glob. Change Biol. 9, 1681-1717.

Robson, T.M., Pancotto, V.A., Flint, S.D., Ballaré, C.L., Sala, O.E., Scopel, A.L., Caldwell, M.M., 2003. Six years of solar UV-B manipulations affect growth of Sphagnum and vascular plants in a Tierra del Fuego peatland. New Phytol. 160, 379-389.

Ruhland, C.T., Day, T.A., 2000. Effects of ultraviolet-B radiation on leaf elongation, production and phenylpropanoid concentrations of Deschampsia antarctica and Colobanthus quitensis in Antarctica. Physiol. Plantarum 109, 244-251.

Ruhland, C.T., Day, T.A., 2001. Size and longevity of seed banks in Antarctica and the influence of ultraviolet-B radiation on survivorship, growth and pigment concentrations of Colobanthus quitensis seedlings. Environ. Exp. Bot. 45, 143-154. 
Searles, P.S., Flint, S.D., Caldwell, M.M., 2001. A meta-analysis of plant field studies simulating stratospheric ozone depletion. Oecologia 127, 1-10.

Xiong, F.S., Day, T.A., 2001. Effect of solar ultraviolet-B radiation during springtime ozone depletion on photosynthesis and biomass production of Antarctic vascular plants. Plant Physiol. $125,738-751$. 
Table 1. Pearson's product-moment correlation coefficients $(r)$ for associations between percentage UV-B transmission and pigment concentrations or chlorophyll $a / b$ ratio at each sampling date. Values significant at $P<0.05$ and $P<0.01$ are denoted by $(*)$ and $(* *)$, respectively.

\begin{tabular}{lcccc}
\hline Date & $\begin{array}{c}\text { Anthocyanin-like } \\
\text { pigment }\end{array}$ & $\begin{array}{c}\text { Total } \\
\text { chlorophyll }\end{array}$ & $\begin{array}{c}\text { Chlorophyll } a / b \\
\text { ratio }\end{array}$ & $\begin{array}{c}\text { UV-B screening } \\
\text { pigments }\end{array}$ \\
\hline 17 Nov & 0.111 & 0.288 & 0.382 & 0.379 \\
$19 \mathrm{Nov}$ & -0.267 & 0.752 & -0.500 & 0.272 \\
$24 \mathrm{Nov}$ & 0.560 & -0.016 & -0.646 & 0.707 \\
$1 \mathrm{Dec}$ & 0.496 & 0.066 & -0.180 & $0.859(*)$ \\
$8 \mathrm{Dec}$ & -0.038 & 0.356 & -0.626 & $0.809(*)$ \\
$15 \mathrm{Dec}$ & $0.947(* *)$ & 0.249 & 0.792 & $0.950(* *)$ \\
$22 \mathrm{Dec}$ & $0.809(*)$ & $-0.854(*)$ & -0.741 & 0.169 \\
\hline
\end{tabular}


Table 2. Slopes of associations between time (day) and pigment concentrations or chlorophyll $a / b$ ratio at different UV-B transmission levels \pm standard error. Slopes significant at $P<0.05$ and $P<0.01$ are denoted by $(*)$ and $(* *)$, respectively. Those within the same column marked with distinct letters are significantly different at $P<0.05$. See Materials and Methods for details of how data were expressed in these analyses.

\begin{tabular}{|c|c|c|c|c|}
\hline $\begin{array}{c}\text { UV-B } \\
\text { transmission (\%) }\end{array}$ & $\begin{array}{c}\text { Anthocyanin-like } \\
\text { pigment }\end{array}$ & Total chlorophyll & $\begin{array}{l}\text { Chlorophyll } \\
a / b \text { ratio }\end{array}$ & $\begin{array}{c}\text { UV-B screening } \\
\text { pigments }\end{array}$ \\
\hline 31 & $0.147^{\mathrm{a}} \pm 0.093$ & $0.027^{\mathrm{a}} \pm 0.012$ & $0.005 \pm 0.018$ & $22.5 \pm 12.6$ \\
\hline 41 & $0.153 \pm 0.163$ & $0.029^{\mathrm{a}} \pm 0.005(* *)$ & $0.005 \pm 0.015$ & $4.5 \pm 16.3$ \\
\hline 48 & $0.189 \pm 0.191$ & $0.013^{\mathrm{a}} \pm 0.005\left(^{*}\right)$ & $0.008 \pm 0.014$ & $19.8 \pm 8.8$ \\
\hline 68 & $0.224 \pm 0.148$ & $-0.006^{b} \pm 0.007$ & $0.010 \pm 0.014$ & $5.1 \pm 13.8$ \\
\hline 79 & $0.399^{b} \pm 0.105\left(^{*}\right)$ & $0.010^{\mathrm{ab}} \pm 0.006$ & $0.010 \pm 0.013$ & $11.1 \pm 14.1$ \\
\hline 100 & $0.321 \pm 0.175$ & $-0.005^{b} \pm 0.006$ & $0.012 \pm 0.012$ & $26.1 \pm 8.8(*)$ \\
\hline
\end{tabular}


Figure legends

Fig. 1. A screen used in the study deployed over Cephaloziella varians at Rothera Point. Note the holes in the Mylar polyester mounted between two plexiglass panes. $C$. varians is the darkly pigmented plant in the foreground. The green plant to the rear is the moss Sanionia uncinata.

Fig. 2. (a) $\mathrm{O}_{3}$ column depth above Rothera Point, (b) daily UV-B $\mathrm{BE}_{\mathrm{BE}}$ dose, (c) daily PAR dose and (d) daily mean air temperatures recorded during the study. Arrows on the $x$-axis denote sampling days. Inset in (a) is daily UV-B $\mathrm{B}_{\mathrm{BE}}$ dose as a function of $\mathrm{O}_{3}$ column depth $(r=-0.823, P<0.001)$. Note that $\mathrm{O}_{3}$ column data were not available for 17 November and 13-22 December, and that radiative data for 25 and 26 November and 19-22 December were recorded at Palmer station on Anvers Island.

Fig. 3. (a) Output from a broad band UV-B sensor placed under each of the five different screen types $(\bullet)$ and from a sensor placed outside the screens (०) on five separate days. Sensor output was linearly associated with irradiances (in $\mathrm{W} \mathrm{m}^{-2}$ ) of unweighted UV-B (output $=0.084+1.738 \times \mathrm{UV}-\mathrm{B} ; r=$ $0.992, P<0.001)$ and UV-B ${ }_{\mathrm{BE}}$ (output $\left.=0.142+16.244 \times \mathrm{UV}-\mathrm{B}_{\mathrm{BE}}, r=0.977, P<0.001\right)$. (b) Percentage difference between the output of the sensor outside the screens and that of the sensor under each screen type.

Fig. 4. Concentrations of pigments as functions of UV-B transmission; (a) anthocyanin-like pigment on 15 December and (b) 22 December, (c) chlorophyll on 22 December, (d) UV-B screening pigments on 1 December, (e) 8 December and (f) 15 December. Data are expressed per g dry weight of tissue. Bars are standard errors, $n=2$ at each transmission level except for the $68 \%$ and $100 \%$ transmission levels, at which $n=1$ and 3, respectively. Inset in (f) is $r$ values derived for UV-B screening pigments as a function of UV-B ${ }_{\mathrm{BE}}$ dose received by plants in the $5.5 \mathrm{~h}$ before each sampling $(r=0.829, P<0$. 
Fig 1

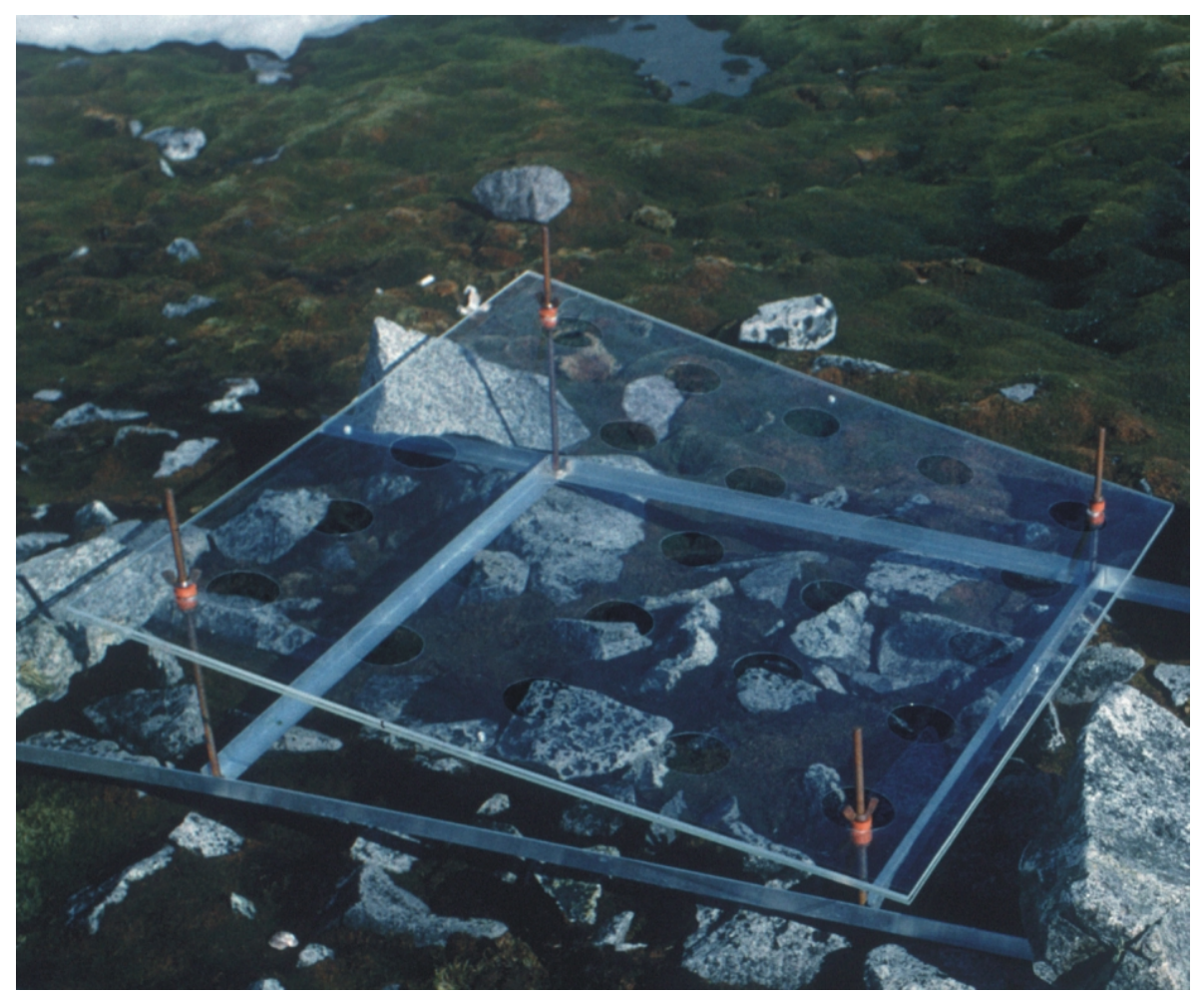


Fig. 2
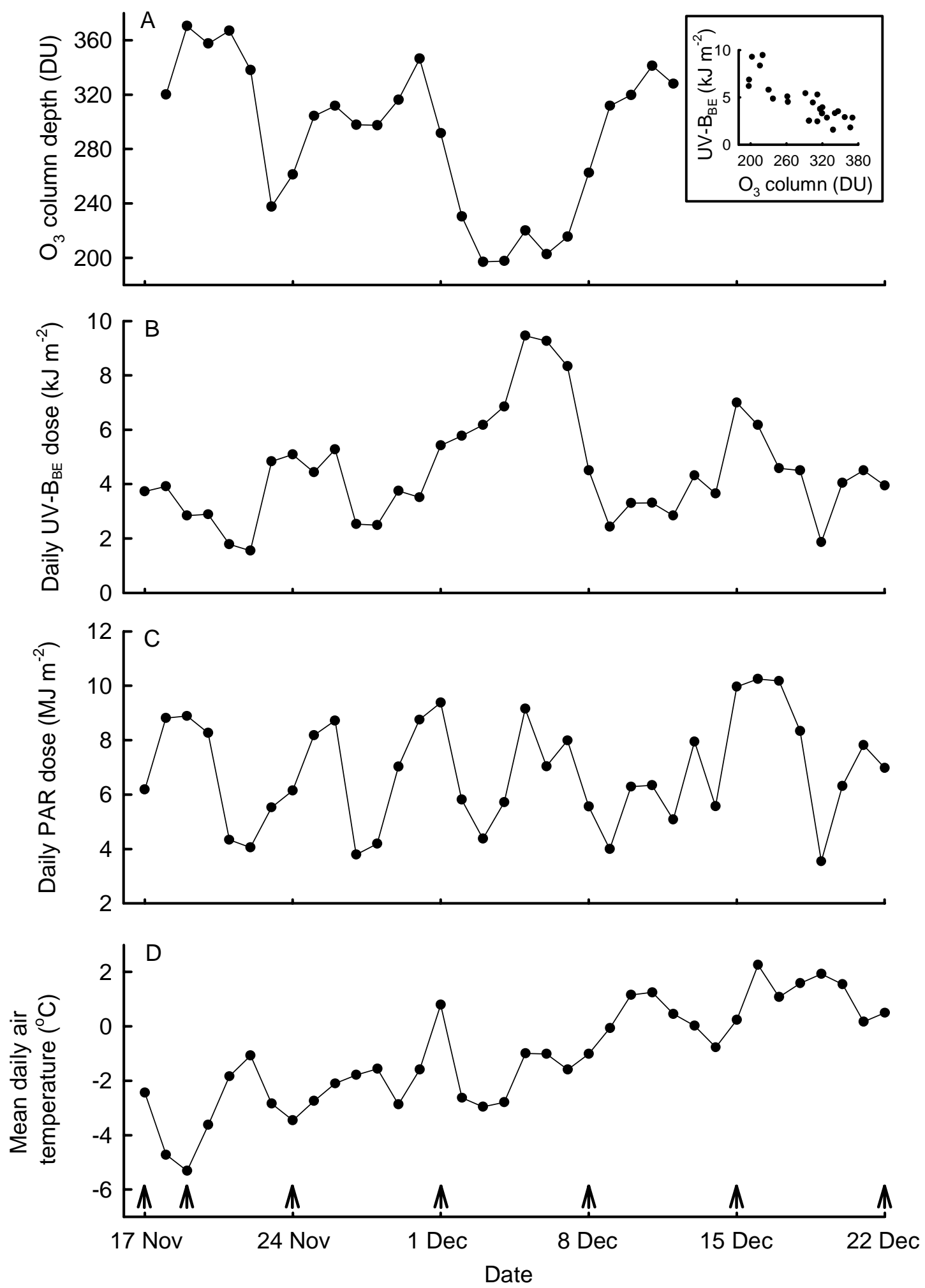
Fig. 3
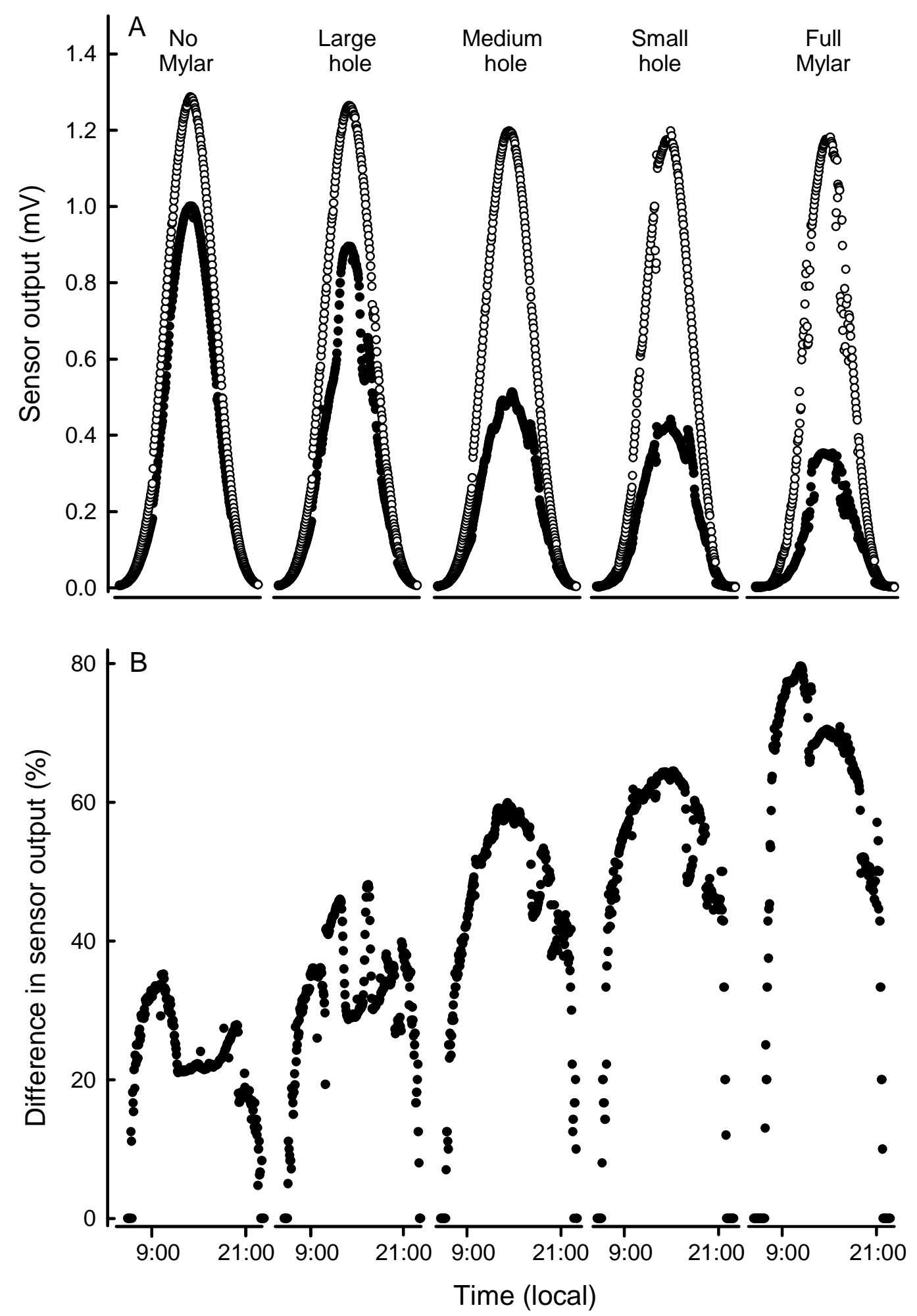
Fig. 4
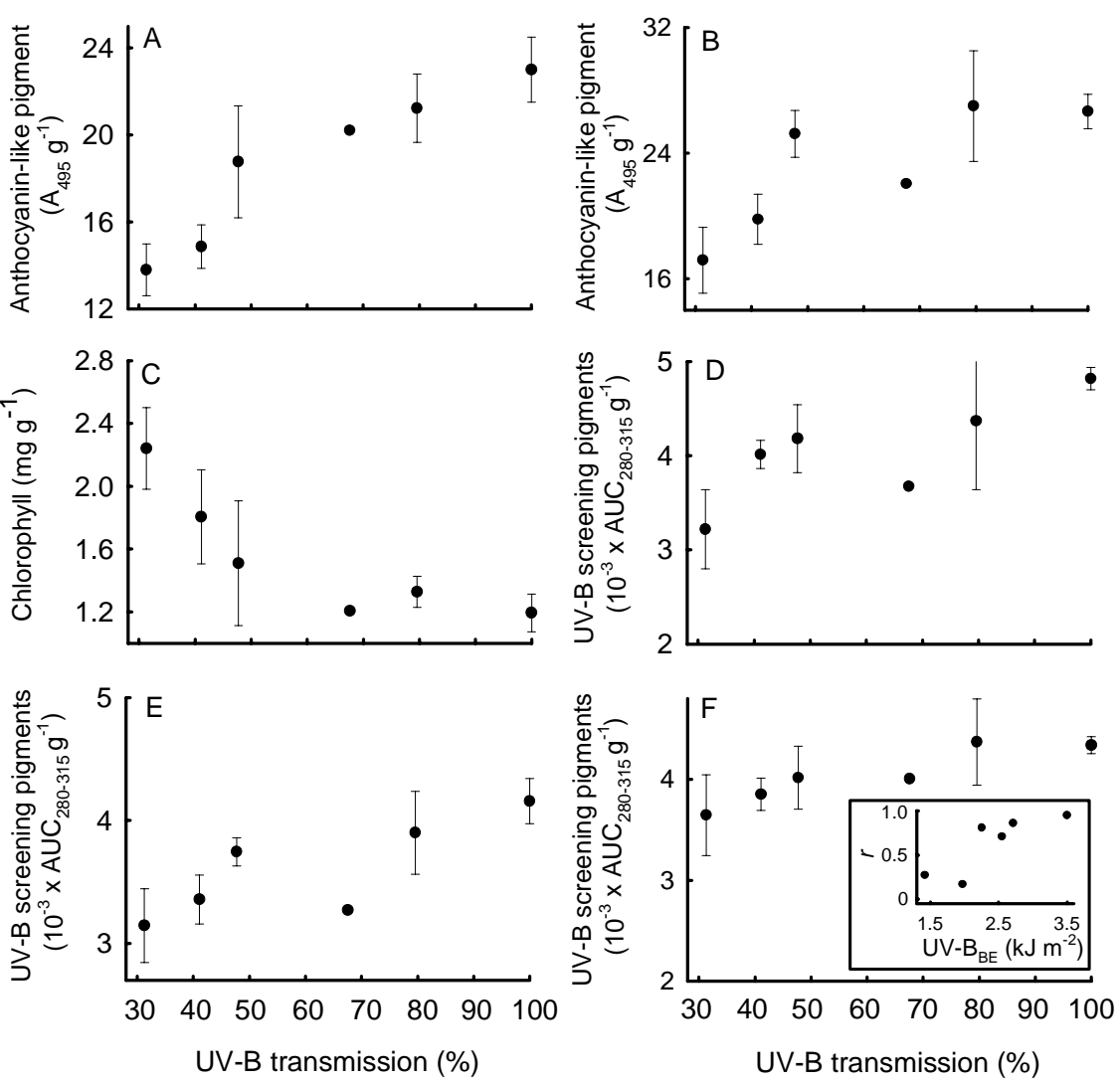